\title{
QT interval as a cardiac risk factor in a middle aged population
}

\author{
J Karjalainen, A Reunanen, P Ristola, M Viitasalo
}

\begin{abstract}
Objective-To evaluate the value of QT interval as a cardiac risk factor in middle aged people.

Methods-The association between QT interval and cardiac risk factors and mortality in a middle aged Finnish population of 5598 men and 5119 women was evaluated over a 23 year follow up. To adjust the QT interval confidently for heart rate, a nomogram was constructed from the baseline electrocardiograms separately for men and women.
\end{abstract}

Results-Nomogram-corrected QT interval $\left(\mathbf{Q T}_{\mathrm{Nc}}\right)$ prolongation was associated with elevated blood pressure and signs of cardiovascular disease; $\mathbf{Q T}_{\mathrm{Nc}}$ shortening was associated with smoking. Over $10 \%$ prolongation of $\mathbf{Q T} \mathbf{N}_{\mathrm{Nc}}$ predicted death in men with heart disease: adjusted relative risk (RR) was $2 \cdot 17$ (95\% confidence interval $0 \cdot 67-7 \cdot 45$ ) for sudden death; $2 \cdot 12$ (1.25-3.59) for total cardiovascular mortality; and 1.92 (1.23-3.00) for all cause mortality. In healthy men the increase in $R R$ was not significant: sudden death, 1.48 (0.67-3.25); total cardiovascular mortality, $1.25(0.92-1.70)$; all cause mortality, 1.21 $(0.96-1 \cdot 53)$. However, healthy men with long $\mathbf{Q T}_{\mathrm{Nc}}$ in the lowest heart rate quartile exhibited an RR of $2.75(1.00-7 \cdot 40)$ for sudden death. Over $10 \%$ shortened $\mathbf{Q T}_{\mathrm{Nc}}$ predicted cardiovascular death in men with heart disease who smoked; RR 3.72 (1.45-9.54). Non-smoking men with short $\mathbf{Q T}_{\mathrm{Nc}}$ had low mortality risks irrespective of possible signs of cardiovascular disease. The trends in mortality risks were similar but weaker for women.

Conclusions-In a middle aged population, prolonged QT interval predicts cardiac mortality in men with signs of cardiovascular disease. In women and healthy men this risk is weak and may reflect subclinical heart disease. A shortened QT interval predicts death in men with heart disease who smoke.

(Heart 1997;77:543-548)

Keywords: QT interval; cardiovascular mortality; cardiac risk factors; smoking

The QT interval in the electrocardiogram reflects the time registered for depolarisation and repolarisation of the ventricular myocardium - that is, the summation of action potential durations in the ventricles. ${ }^{1}$ Theoretically, long and disparate duration of ventricular action potentials predispose to reentrant ventricular arrhythmias, which are harbingers of sudden death especially in cardiac patients. ${ }^{2}$ Short action potentials, on the other hand, reflect rapid electrical recovery enabling short cycle length in ventricular arrhythmias ${ }^{3}$ and may predispose to ventricular fibrillation. Factors influencing action potentials change the QT interval; heart rate and autonomic tone are particularly important. ${ }^{4}$ For clinical and research purposes, QT intervals are corrected for heart rate. The most widely used method is based on Bazett's formula, despite the fact that this equation over corrects the QT interval at high heart rates and under corrects it at low heart rates. ${ }^{5}$

Clinical studies in subjects with congenital or acquired long QT syndrome and in patients with acute myocardial infarction have shown that long QT intervals predispose to malignant ventricular arrhythmias and sudden death. ${ }^{67}$ In epidemiological studies, however, the association between the length of the QT interval and the risk of cardiovascular mortality remains controversial..$^{8-10}$ The explanation may be the weakness of the QT interval as a risk predictor, further obscured by the inadequate Bazett's method for adjusting the QT values for heart rate. Heart rate has been found to predict cardiac mortality. ${ }^{11}$

We have recently created a nomogram to adjust the QT intervals for heart rate that is superior in accuracy to Bazett's and other methods. ${ }^{5}$ In this study, we used this nomogram principle to explore the value of QT interval as a cardiac risk factor in a middle aged Finnish population.

\section{Methods}

\section{STUDY POPULATION}

The study population consisted of the original cohort of 11026 people participating in the Social Insurance Institution's Coronary Heart Disease Study. ${ }^{12} 13$ Subjects were aged between 30 and 59 years at study entry in 1966-72. The study population was taken from four areas (south-western, western, central, eastern) of Finland, and was a representative sample of the middle aged Finnish population. Of those invited to the initial examination the participation rate was $89 \%$ in men and $91 \%$ in women; 309 people were excluded from the study for missing data (232) or because of bundle branch block or second to third degree atrioventricular block (77), leaving 5598 men and 5119 women in the study group. 
Data analysis was made for the whole study group and for a subgroup free from known cardiovascular diseases. Exclusions from this subgroup were subjects with known heart disease, effort angina or signs of myocardial infarction in the electrocardiogram (Minnesota codes $1 \cdot 1$, or $1 \cdot 2$, and $5 \cdot 1-5 \cdot 2$ ), and subjects who used digitalis, nitroglycerin or antiarrhythmic drugs. The subgroup comprised 5103 men and 4785 women. Data analysis was also made separately for the excluded subgroup of 495 men and 334 women with signs of cardiovascular disease.

\section{EVALUATION OF CARDIAC RISK FACTORS}

The procedure for the baseline examination has previously been described in detail. ${ }^{12}{ }^{13}$ Briefly, it consisted of a questionnaire on the history of previous diseases, drug therapy, and smoking habits, an interview on cardiovascular symptoms, and a rest electrocardiogram based on the Minnesota code. Casual blood pressure, body mass index (weight $\mathrm{kg} /$ height $\mathrm{m}^{2}$ ), and serum cholesterol were measured.

\section{QT INTERVAL ANALYSIS}

Rest electrocardiograms (12 lead) were recorded at a paper speed of $50 \mathrm{~mm} / \mathrm{s}$ at baseline. They were analysed by nine trained readers as reported earlier. ${ }^{14}$ Lead I, II, or III was chosen for the QT interval measurement on the basis of the visually longest QT interval. The measurement was made from the beginning of the QRS complex to the end of the $T$ wave

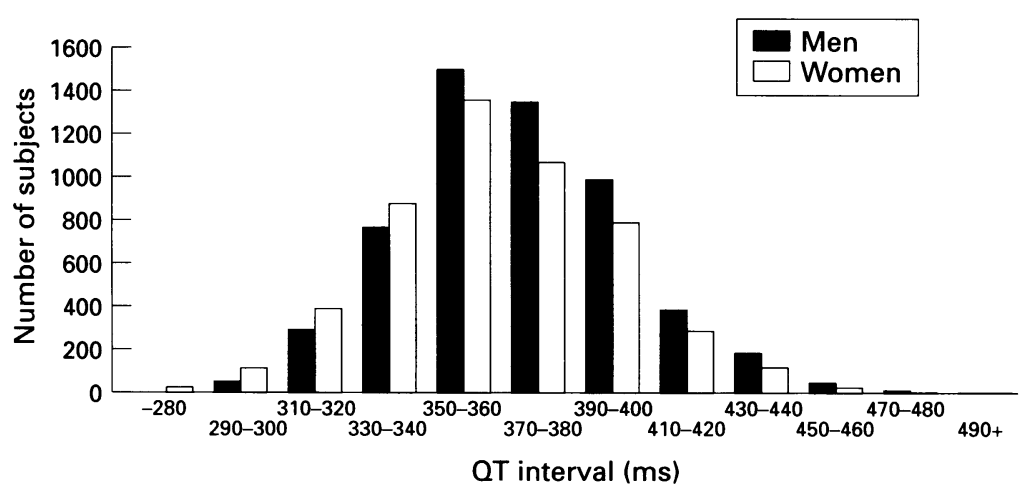

Figure $1 Q T$ intervals in the whole study population.

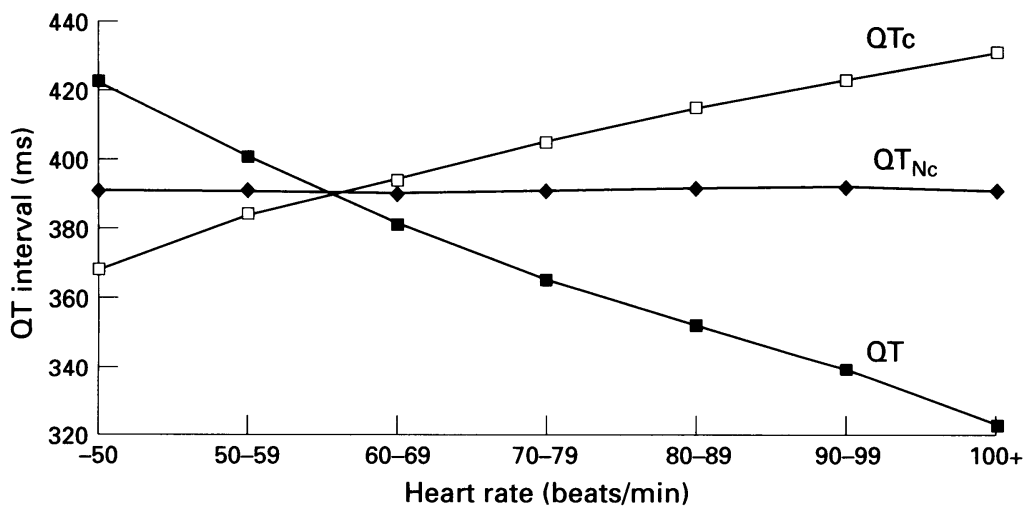

Figure 2 The QT-heart rate relationship curve in men of the study population. Heart rate adjustment with the nomogram method $\left(Q T_{N c}\right)$ gives adjusted values close to the reference $Q T$ interval of $391 \mathrm{~ms}$ at all heart rates. For comparison, $Q T_{c}$ values obtained with Bazett's equation are shown. Data points are mean values at different heart rate subranges. where the terminal limb joins the TP baseline. Heart rate was the mean of two measurements from both ends of the lead I recording.

To adjust the measured QT interval for heart rate, a curve relating QT intervals and heart rates was constructed ${ }^{5}$ from the baseline electrocardiograms. Mean QT intervals at different heart rate ranges of five beats/min were plotted against the corresponding mean heart rates, and the best fitting curve relating QT intervals and heart rates was constructed visually. This was done separately for men and women. The QT interval at 60 beats/min was the reference QT interval-391 ms in men and $397 \mathrm{~ms}$ in women in the study population. The deviation of the QT interval-heart rate curve from the reference value at different heart rates generated the numbers for the adjustment nomogram. The nomogram corrected QT value was calculated as: $\mathrm{QT}_{\mathrm{Nc}}=\mathrm{QT}+$ correction number. For data analysis, the following five $\mathrm{QT}_{\mathrm{Nc}}$ categories were created: $\mathrm{QT}_{\mathrm{Nc}}$ compared with reference QT interval was within 5\%, 5-10\% shorter, $>10 \%$ shorter, $5-10 \%$ longer, and $>10 \%$ longer.

\section{END POINTS}

The study end points were death from all causes (total mortality), death from all cardiovascular diseases, death from coronary artery disease (lethal outcome for a patient hospitalised for myocardial infarction or death outside the hospital probably caused by coronary artery disease), and sudden cardiac death (deaths ensuing within one hour of symptom onset).

The mortality of the study population has been monitored continuously. Copies of death certificates of the deceased were obtained from the Central Statistical Office of Finland and additional information from the hospital and necropsy records were sought when needed. ${ }^{1315}$ Deaths until the end of 1992 are included in the analyses for this report. However, sudden deaths are included only until the end of 1979, because a detailed analysis of time from onset of symptoms to the time of death was available only for these cases. ${ }^{15}$

\section{STATISTICAL ANALYSIS}

Associations between the $\mathrm{QT}_{\mathrm{Nc}}$ categories and risk factors were estimated based on the general linear model. ${ }^{16}$ The Cox proportional hazards model was used in the mortality analyses. ${ }^{17}$ Relative mortality risks were computed using the middle $\mathrm{QT}_{\mathrm{Nc}}$ category $\left(\mathrm{QT}_{\mathrm{Nc}}\right.$ deviated less than $5 \%$ from the reference QT interval) as the reference category, and separately in both sexes. To adjust for risk factors subjects were divided by: age (into five-year groups); current smokers and non-smokers; four blood pressure groups (using the cut-points $140 / 90 \mathrm{~mm} \mathrm{Hg}$, $160 / 95 \mathrm{~mm} \mathrm{Hg}$, and $170 / 100 \mathrm{~mm} \mathrm{Hg}$, and/or antihypertensive treatment); serum cholesterol (cut off $7 \cdot 2 \mathrm{mmol} / \mathrm{l}$, exceeded by $20 \%$ of the population); body mass ( 30 was used to define subjects as obese or non-obese); and diabetes (all subjects with a known history). Statistical significances were tested using the likelihood ratio test based on Cox's models. 
Table $1 Q T_{N_{c}}$ categories, number (\%) of subjects and cut points

\begin{tabular}{llllll}
\hline & $>10 \%$ shortened & $5-10 \%$ shortened & $\begin{array}{l}\text { Within } 5 \% \\
\text { (reference values) }\end{array}$ & $5-10 \%$ prolonged & $>10 \%$ prolonged \\
\hline Men, number (\%) & $131(2 \cdot 3)$ & $760(13 \cdot 6)$ & $3764(67 \cdot 2)$ & $736(13 \cdot 1)$ & $207(3 \cdot 7)$ \\
$\mathrm{QT}_{\mathrm{Nc}}(\mathrm{ms})$ & $<353$ & $353-371$ & $372-410$ & $411-430$ & $>430$ \\
Women, number (\%) $_{\mathrm{QT}_{\mathrm{Nc}}(\mathrm{ms})}^{112(2 \cdot 2)}$ & $650(12 \cdot 7)$ & $3554(69 \cdot 4)$ & $629(12 \cdot 3)$ & $174(3 \cdot 4)$ \\
\hline
\end{tabular}

\section{Results}

QT INTERVAL ANALYSIS

QT intervals in the whole study population are shown in figure 1 . The nomogram method gave an excellent adjustment of the QT intervals for heart rate at all heart rates (fig 2). Mean $\mathrm{QT}_{\mathrm{Nc}}$ values at different heart rate ranges differed less than $1 \mathrm{~ms}$ from the reference QT interval in both men and women. The nomogram adjusted the QT intervals confidently in individuals with heart disease, mean $\mathrm{QT}_{\mathrm{Nc}}$ values at different heart rates differed no more than $2 \mathrm{~ms}$ from the reference QT interval in subjects with heart disease.

We classified the $Q T_{\mathrm{Nc}}$ values into the five categories as shown in table 1 . The $\mathrm{QT}_{\mathrm{Nc}}$ was prolonged by more than $10 \%$ ( $>430 \mathrm{~ms}$ in men and $>437 \mathrm{~ms}$ in women) in $3.7 \%$ of men and $3 \cdot 4 \%$ of women.

$\mathrm{QT}_{\mathrm{NC}}$ CATEGORIES, RISK FACTORS, AND SIGNS OF CARDIOVASCULAR DISEASE

Aging prolonged $\mathrm{QT}_{\mathrm{Nc}}$ by $0 \cdot 1 \%$ per year in men and $0.05 \%$ per year in women. After adjustment for age, blood pressure (systolic and diastolic) and hypertension were associated with longer $\mathrm{QT}_{\mathrm{Nc}}$ intervals in both men and women (table 2). In contrast, smoking was associated with shorter $\mathrm{QT}_{\mathrm{Nc}}$ intervals. Prevalence of diabetes was increased in men with moderately $(5-10 \%)$ prolonged $\mathrm{QT}_{\mathrm{Nc}}$. Serum cholesterol concentration or body mass index were not associated with $\mathrm{QT}_{\mathrm{Nc}}$.

Because elevated blood pressure and smoking had opposite effects on QT interval, we analysed non-smoking and normotensive men separately. In non-smoking men the prevalence of elevated blood pressure $(140 / 90 \mathrm{~mm}$ $\mathrm{Hg}$ or more) in the longest $\mathrm{QT}_{\mathrm{Nc}}$ category was 2.3 times that in the shortest $\mathrm{QT}_{\mathrm{Nc}}$ category. In normotensive men the prevalence of smoking in the shortest $\mathrm{QT}_{\mathrm{Nc}}$ category was 3.0 times that in the longest $\mathrm{QT}_{\mathrm{Nc}}$ category.

$\mathrm{QT}_{\mathrm{Nc}}$ value was associated with the signs of cardiovascular disease. Exclusions from the total study population when forming the "healthy" subpopulation were most common in the category with the longest QT interval (table 2).

\section{MORTALITY}

Until the end of 1992,1848 men $(33.0 \%)$ and 840 women $(16.4 \%)$ had died. The respective numbers in the population free from cardio-

Table 2 Age, age adjusted cardiac risk factors, and exclusions in different $Q T_{N c}$ categories in the total study population

\begin{tabular}{|c|c|c|c|c|c|c|}
\hline Risk factor & $>10 \%$ shortened & $5-10 \%$ shortened & Within 5\% & 5-10\% prolonged & $>10 \%$ prolonged & $P$ \\
\hline \multicolumn{7}{|l|}{ Men } \\
\hline Age (years) & 42 & 42 & 43 & 45 & 47 & $<0.001$ \\
\hline Serum cholesterol $(\mathrm{mmol} / \mathrm{l})$ & 6.5 & 6.6 & $6 \cdot 5$ & 6.5 & 6.4 & NS \\
\hline Systolic blood pressure $(\mathrm{mm} \mathrm{Hg})$ & 133 & 136 & 139 & 140 & 146 & $<0.001$ \\
\hline Diastolic blood pressure $(\mathrm{mm} \mathrm{Hg})$ & 78 & 80 & 81 & 81 & 84 & $<0.001$ \\
\hline Hypertension $(\%)^{\star}$ & 2 & 4 & 5 & 6 & 11 & $<0.001$ \\
\hline Body mass index $\left(\mathrm{kg} / \mathrm{m}^{2}\right)$ & 25 & 26 & 26 & 25 & 25 & NS \\
\hline Smokers (\%) & 61 & 56 & 53 & 51 & 44 & $<0.05$ \\
\hline Diabetes (\%) & $1 \cdot 6$ & 1 & 2 & $3 \cdot 3$ & 1.9 & $<0.01$ \\
\hline Exclusions (\%) & $9 \cdot 9$ & $6 \cdot 7$ & $8 \cdot 2$ & $12 \cdot 9$ & 14 & $<0.001$ \\
\hline \multicolumn{7}{|l|}{ Women } \\
\hline Age (years) & 43 & 43 & 44 & 45 & 47 & $<0.001$ \\
\hline Serum cholesterol $(\mathrm{mmol} / \mathrm{l})$ & $6 \cdot 5$ & $6 \cdot 6$ & $6 \cdot 5$ & 6.5 & $6 \cdot 5$ & NS \\
\hline Systolic blood pressure $(\mathrm{mm} \mathrm{Hg})$ & 136 & 135 & 138 & 140 & 144 & $<0.001$ \\
\hline Diastolic blood pressure ( $\mathrm{mm} \mathrm{Hg}$ ) & 83 & 82 & 83 & 84 & 84 & $<0.05$ \\
\hline Hypertension $(\%)^{\star}$ & 12 & 5 & 9 & 12 & 18 & $<0.001$ \\
\hline Body mass index $\left(\mathrm{kg} / \mathrm{m}^{2}\right)$ & 26 & 26 & 26 & 26 & 27 & NS \\
\hline Smokers (\%) & 17 & 17 & 13 & 10 & 12 & $<0.01$ \\
\hline Diabetes (\%) & 1.8 & 1.8 & 1.5 & $1 \cdot 6$ & $2 \cdot 3$ & NS \\
\hline Exclusions (\%) & $7 \cdot 1$ & $4 \cdot 8$ & $6 \cdot 3$ & $8 \cdot 7$ & $9 \cdot 2$ & $<0.05$ \\
\hline
\end{tabular}

ॠBlood pressure $170 / 100 \mathrm{~mm} \mathrm{Hg}$ or more, or antihypertensive treatment.

Table 3 Relative risks (RR) for disease, and sudden mortality in different $Q T_{N c}$ categories of the total study population after adjustment for age and confounding risk factors

\begin{tabular}{|c|c|c|c|c|c|c|c|c|c|c|}
\hline & \multicolumn{2}{|c|}{$>10 \%$ shortened } & \multicolumn{2}{|c|}{$5-10 \%$ shortened } & \multicolumn{2}{|c|}{ Within 5\% } & \multicolumn{2}{|c|}{ 5-10\% prolonged } & \multicolumn{2}{|c|}{$>10 \%$ prolonged } \\
\hline & $n$ & $R R(95 \% C I)$ & $n$ & $R R(95 \% C I)$ & $n$ & $R R$ & $n$ & $R R(95 \% C I)$ & $n$ & $R R(95 \% C I)$ \\
\hline \multirow{7}{*}{$\begin{array}{l}\text { Men } \\
\text { All cause } \\
\text { Total } \\
\text { cardiovascular } \\
\text { Coronary artery } \\
\text { disease } \\
\text { Sudden death } \\
\text { Women } \\
\text { All cause } \\
\text { Total } \\
\text { cardiovascular } \\
\text { Coronary } \\
\text { artery disease }\end{array}$} & \multicolumn{2}{|c|}{$(n=131)$} & \multicolumn{2}{|c|}{$(\mathrm{n}=760)$} & \multicolumn{2}{|c|}{$(n=3764)$} & \multicolumn{2}{|c|}{$(n=736)$} & \multicolumn{2}{|c|}{$(n=207)$} \\
\hline & 40 & $1.06(0.78-1.46)$ & 213 & $0.99(0.86-1.15)$ & 1225 & 1.00 & 268 & $0.99(0.86-1.13)$ & 102 & $1 \cdot 33(1 \cdot 08-1 \cdot 63)$ \\
\hline & 20 & $1.04(0.67-1.63)$ & 117 & $1.03(0.85-1.26)$ & 670 & $1 \cdot 00$ & 163 & $1.07(0.90-1.27)$ & 63 & $1.42(1.09-1.84)$ \\
\hline & $\begin{array}{r}13 \\
2\end{array}$ & $\begin{array}{l}0.93(0.54-1.62) \\
0.73(0.18-2.96)\end{array}$ & $\begin{array}{l}89 \\
14\end{array}$ & $\begin{array}{l}1.07(0.85-1.35) \\
0.86(0.49-1.51)\end{array}$ & $\begin{array}{r}484 \\
96\end{array}$ & $\begin{array}{l}1.00 \\
1.00\end{array}$ & $\begin{array}{r}114 \\
27\end{array}$ & $\begin{array}{l}1.04(0.84-1 \cdot 27) \\
1.21(0.79-1.87)\end{array}$ & $\begin{array}{l}45 \\
10\end{array}$ & $\begin{array}{l}1.44(1.06-1.96) \\
1.50(0.78-2.89)\end{array}$ \\
\hline & $(\mathrm{n}=112)(0.77-1.85)$ & $112)(0 \cdot 77-1 \cdot 85)$ & \multicolumn{2}{|c|}{ 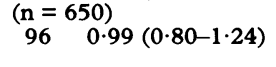 } & \multicolumn{2}{|c|}{$\begin{array}{l}(n=3554) \\
566 \quad 1.00\end{array}$} & \multicolumn{2}{|c|}{$\begin{array}{l}(n=629) \\
119 \quad 1.04(0.85-1 \cdot 26)\end{array}$} & \multicolumn{2}{|c|}{ 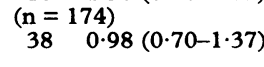 } \\
\hline & 8 & $0.92(0.45-1.86)$ & 48 & $1.04(0.76-1.41)$ & 279 & 1.00 & 64 & $1 \cdot 10(0 \cdot 83-1 \cdot 44)$ & 27 & $1.32(0.89-1.97)$ \\
\hline & 4 & $0.86(0.34-2 \cdot 31)$ & 22 & $0.87(0.56-1.37)$ & 150 & 1.00 & 38 & $1 \cdot 21(0.85-1 \cdot 73)$ & 15 & $1.38(0.81-2.36)$ \\
\hline
\end{tabular}

Relative risks printed in bold differ significantly from the risk in the middle of the $\mathrm{QT}_{\mathrm{Nc}}$ category.

$\mathrm{CI}=$ Confidence interval. 
Table 4 Relative mortality risks $(R R)$ in different $Q T_{N c}$ categories in the population free from cardiovascular disease after adjustment for age and risk factors

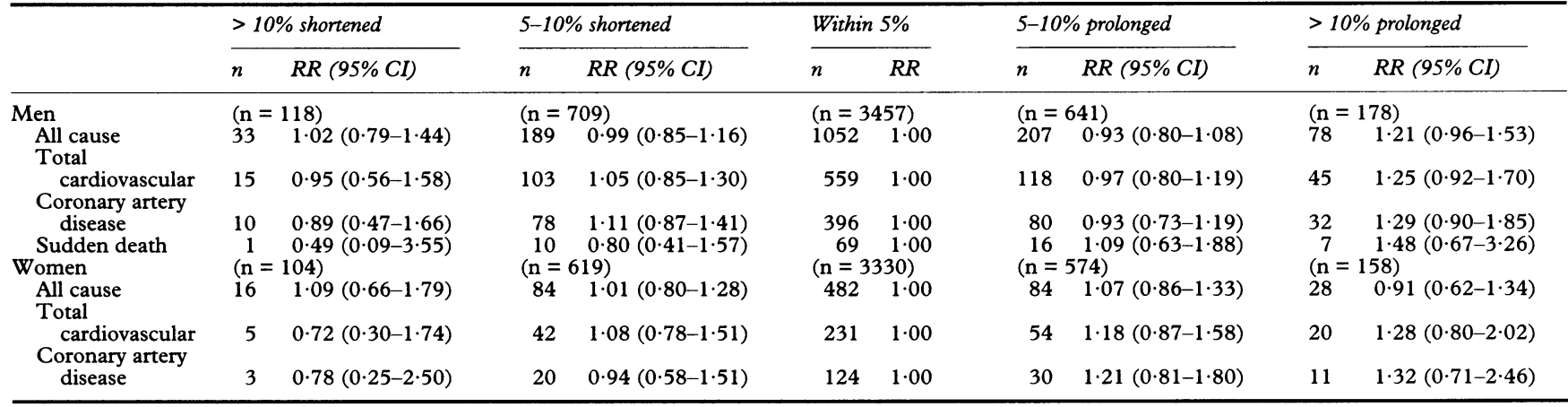

$\mathrm{CI}=$ Confidence interval.

Table 5 Relative mortality risks (RR) in different $Q T_{N c}$ categories in subjects with signs of cardiovascular disease after adjustment for age and risk factors

\begin{tabular}{|c|c|c|c|c|c|c|c|c|c|c|}
\hline & \multicolumn{2}{|c|}{$>10 \%$ shortened } & \multicolumn{2}{|c|}{$5-10 \%$ shortened } & \multicolumn{2}{|c|}{ Within 5\% } & \multicolumn{2}{|c|}{$5-10 \%$ prolonged } & \multicolumn{2}{|c|}{$>10 \%$ prolonged } \\
\hline & $n$ & $R R(95 \% C I)$ & $n$ & $R R(95 \% C I)$ & $n$ & $R R$ & $n$ & $R R(95 \% C I)$ & $n$ & $R R(95 \% C I)$ \\
\hline Men & \multicolumn{2}{|c|}{$(\mathrm{n}=13)$} & \multicolumn{2}{|c|}{$(n=51)$} & \multicolumn{2}{|c|}{$(\mathrm{n}=307)$} & \multicolumn{2}{|c|}{$(\mathrm{n}=95)$} & \multicolumn{2}{|c|}{$(\mathrm{n}=29)$} \\
\hline $\begin{array}{l}\text { All cause } \\
\text { Total }\end{array}$ & 7 & $1 \cdot 26(0 \cdot 59-2 \cdot 71)$ & 24 & $0.99(0.65-1.53)$ & 173 & $1 \cdot 00$ & 61 & $1.22(0.91-1.63)$ & 24 & $1 \cdot 92(1 \cdot 23-3 \cdot 00)$ \\
\hline $\begin{array}{l}\text { cardiovascular } \\
\text { Coronary artery }\end{array}$ & 5 & $1 \cdot 30(0.52-3 \cdot 21)$ & 14 & $0.90(0.51-1.57)$ & 111 & $1 \cdot 00$ & 45 & $1 \cdot 41(1 \cdot 00-2 \cdot 00)$ & 18 & $2 \cdot 12(1 \cdot 25-3 \cdot 59)$ \\
\hline $\begin{array}{l}\text { disease } \\
\text { Sudden death }\end{array}$ & $\begin{array}{l}3 \\
1\end{array}$ & $\begin{array}{l}0.94(0.30-3 \cdot 00) \\
1.25(0.17-9.35)\end{array}$ & $\begin{array}{r}11 \\
4\end{array}$ & $\begin{array}{l}0.93(0.48-1.78) \\
1.15(0.39-3.39)\end{array}$ & $\begin{array}{l}88 \\
27\end{array}$ & $\begin{array}{l}1.00 \\
1.00\end{array}$ & $\begin{array}{l}34 \\
11\end{array}$ & $\begin{array}{l}1.38(0.92-2.08) \\
1.61(0.79-3.82)\end{array}$ & $\begin{array}{r}13 \\
3\end{array}$ & $\begin{array}{l}\mathbf{2} \cdot 11(\mathbf{1} \cdot \mathbf{1 4}-\mathbf{3 \cdot 8 8}) \\
2 \cdot 17(0 \cdot 63-7 \cdot 45)\end{array}$ \\
\hline Women & \multicolumn{2}{|c|}{$(\mathrm{n}=8)$} & \multicolumn{2}{|c|}{$(\mathrm{n}=31)$} & \multicolumn{2}{|c|}{$(n=224)$} & \multicolumn{2}{|c|}{$(n=55)$} & \multicolumn{2}{|c|}{$(n=16)$} \\
\hline All cause & 5 & $1.95(0 \cdot 78-4 \cdot 89)$ & 12 & $0 \cdot 87(0 \cdot 47-1 \cdot 62)$ & 84 & 1.00 & 19 & $0.91(0.54-1.52)$ & 10 & $1.22(0.62-2 \cdot 41)$ \\
\hline $\begin{array}{l}\text { cardiovascular } \\
\text { Coronary artery }\end{array}$ & 3 & $1.80(0.55-5 \cdot 88)$ & 6 & $0.83(0.35-1.95)$ & 48 & $1 \cdot 00$ & 10 & $0.77(0.38-1.54)$ & 7 & $1.50(0.66-3.41)$ \\
\hline disease & 1 & $1 \cdot 20(0 \cdot 16-9.06)$ & 2 & $0 \cdot 50(0 \cdot 12-2 \cdot 15)$ & 26 & $1 \cdot 00$ & 8 & $1 \cdot 18(0 \cdot 52-2 \cdot 66)$ & 4 & $1.62(0.54-4.87)$ \\
\hline
\end{tabular}

Relative risks printed in bold differ significantly from the risk in the middle of the $\mathrm{QT}_{\mathrm{Nc}}$ category.

$\mathrm{CI}=$ Confidence interval.

vascular disease were $1559(30 \cdot 5 \%)$ and 710 $(14 \cdot 8 \%)$. In the group with signs of cardiovascular disease, $289(58.4 \%)$ of the men and 130 $(38.9 \%)$ of the women had died. Until the end of 1979,149 men and 18 women had died suddenly. Because of the small number of cases among women, the relative risks for sudden death could not be confidently calculated and are not presented.

Among the total study population, men with more than $10 \%$ prolongation of $\mathrm{QT}_{\mathrm{Nc}}$ intervals had significantly elevated age adjusted relative risk ratios for all cause mortality $(1 \cdot 40)$, total cardiovascular mortality $(1.53)$, and coronary mortality $(1.53)$. The relative risk was greatest for sudden death (1.63); however, because of the small number of cases the increase in the risk was not significant. Increased death risks were weakened after adjustment for other cardiovascular risk factors, but the order of the risk ratios was the same (table 3 ). In women, the age adjusted relative risk for total cardiovascular mortality was significantly elevated $(1.50)$ in the longest $\mathrm{QT}_{\mathrm{Nc}}$ group but not for all cause mortality $(1 \cdot 07)$. After adjustment for other risk factors, no significant differences in relative mortality risks between $\mathrm{QT}_{\mathrm{Nc}}$ categories were found in women.

\section{Normal population}

After excluding subjects with signs of cardiovascular disease and adjusting for cardiac risk factors, there was still a tendency of greater mortality in the longest $\mathrm{QT}_{\mathrm{Nc}}$ category, especially in men, but the differences were not sig- nificant (table 4). However, in a subanalysis of sudden death, the risk ratio was greatest in the lowest heart rate quartile (below 63 beats/min) with more than $10 \% \mathrm{QT}_{\mathrm{Nc}}$ prolongation ( $\mathrm{RR}$ $2 \cdot 75 ; 95 \%$ confidence intervals (CI) $1 \cdot 00-7 \cdot 60$ ).

PROGNOSTIC VALUE OF QT INTERVAL IN MEN WITH HEART DISEASE

We studied the predictive value of the $\mathrm{QT}_{\mathrm{Nc}}$ interval for death in the "excluded" subjects after adjusting for confounding risk factors. In men with signs of cardiovascular diseases the two longest $\mathrm{QT}_{\mathrm{Nc}}$ categories were associated with increased mortality risks (table 5). There was also an increased risk trend in the shortest $\mathrm{QT}_{\mathrm{Nc}}$ category, which was associated with smoking. When men with signs of cardiovascular diseases who smoked were analysed separately, their relative risk in the shortest $\mathrm{QT}_{\mathrm{Nc}}$ category for all cause mortality was $2 \cdot 85(95 \%$ CI, 1.23-6.63), for cardiovascular mortality it was $3.72(1.45-9.54)$ (fig 3 ), and for sudden death $2.84(0 \cdot 36-22 \cdot 54)$. However, these risk estimations are based on a small number of cases as only 13 men with heart disease had a more than $10 \%$ shortened $\mathrm{QT}_{\mathrm{Nc}}$ (table 5). All five men with cardiovascular death in this group smoked, while only one of the six surviving men smoked. Among the non-smoking men, a short QT interval seemed to protect from cardiovascular death in both "healthy" men and those with signs of cardiovascular disease. A U-shaped risk profile was also seen in smoking women, but the differences in relative mortality risks between the $\mathrm{QT}_{\mathrm{Nc}}$ categories were not significant. 


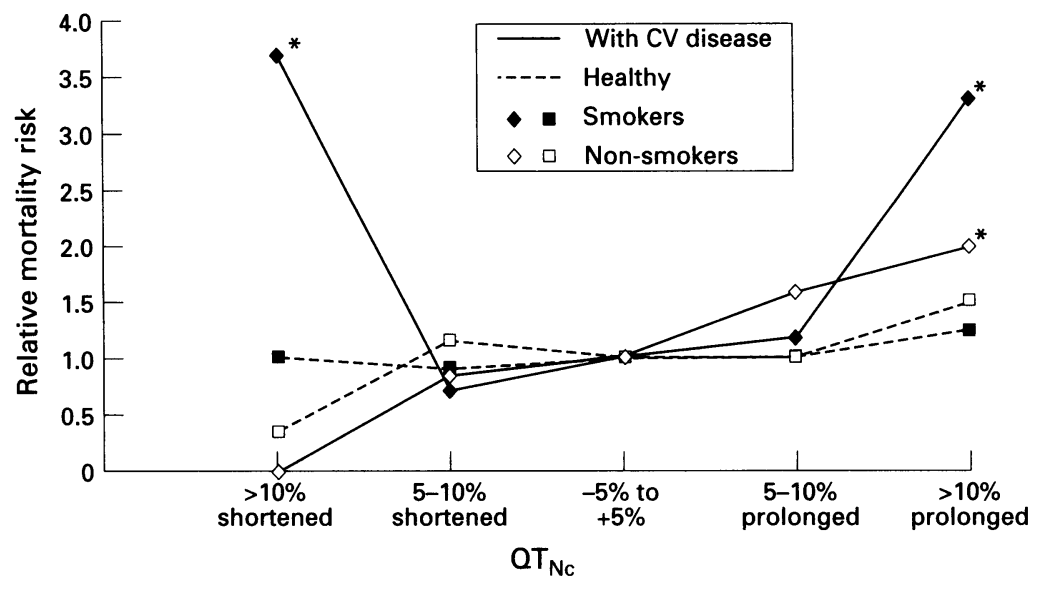

Figure 3 Relative risks for cardiovascular death in different $Q T_{N_{c}}$ categories of smoking and non-smoking men. $C V$, cardiovascular. ${ }^{\star}$ Mortality risk differs significantly from the risk in the middle $Q T_{N c}$ category. to excess mortality even in the "healthy" subpopulation with longest $\mathrm{QT}_{\mathrm{Nc}}$ intervals may reflect the increased risk due to undiagnosed pathological left ventricular hypertrophy or other heart pathology.

Smokers exhibited shorter QT intervals than non-smokers. Smoking increases sympathetic tone, ${ }^{22}$ and heart rate variability changes in smokers point to decreased vagal control of the heart. ${ }^{23}$ Both these effects shorten the QT inter$\mathrm{val}^{24}{ }^{25}$ and increase the arrhythmia risk. ${ }^{26} 27$

The U-shaped risk profile observed among smokers with signs of cardiovascular disease (fig 3 ) is unexpected. Although this finding is based on a small number of smoking subjects with heart disease, it may explain why short QT interval tended to increase risk in the Framingham study. ${ }^{8}$ When subjects with heart disease suffer acute myocardial infarction the typical automatic rhythm disturbances may have faster rates as a consequence of short QT interval and enhanced sympathetic activity. Combined with reduced vagal activity the risk of ventricular fibrillation then rises. ${ }^{27}$ On the other hand, a long QT interval, including increased dispersion of repolarisation in diseased heart, favours re-entrant mechanisms of ventricular arrhythmias. ${ }^{28}$ When this is accompanied by smoking enhanced sympathetic activity, the susceptibility to non-sustained and sustained ventricular tachycardias increases, as recently shown by Huikuri et al in patients with arrhythmias. ${ }^{29}$ Thus, the arrhythmic mechanisms may also contribute to the U-shaped risk profile among smokers. It should be noted that smoking cessation is accompanied by a marked reduction of arrhythmic death in high risk subjects. ${ }^{30}$ On the other hand, smoking is a strong risk factor and can cause death by many mechanisms other than arrhythmia. In fact, the increased mortality risks and short QT in smokers may reflect heavy smoking.

One limitation of our study is that we were unable to analyse any impact of alcohol consumption or physical activity, both of which may influence the QT interval and mortality. ${ }^{2031}$ Another limitation is the absence of sudden death data beyond 1979. However, in the case of sudden death the importance of a follow up longer than 10 years may be questioned. For QT interval measurements only leads I, II, and III were used as in other population studies. ${ }^{932}$ Thus the measured QT interval may have been too short in some cases. cardiovascular disease. Some of these five men $(0.1 \%$ of men without signs of cardiovascular disease) may have represented latent forms of long QT syndrome. Patients with this syndrome usually have low heart rate $^{19}$ and no signs of structural heart disease.

\section{ASSOCIATION BETWEEN QT INTERVAL AND CARDIAC RISK FACTORS}

Subjects with longer $\mathrm{QT}_{\mathrm{Nc}}$ had higher blood pressure, possibly because the QT interval is prolonged when left ventricular mass increases. ${ }^{20}$ Moreover, we found QT interval prolongation to be associated with signs of cardiovascular disease. Subclinical disease has been identified as an independent risk factor for cardiovascular mortality. ${ }^{21}$ In fact, the tendency

\section{EARLIER STUDIES AND METHODOLOGICAL} ASPECTS

Most studies using Bazett's $\mathrm{QT}_{\mathrm{c}}$ values have shown increased mortality in subjects with cardiovascular diseases and long QT interval, as reviewed by Algra et al. ${ }^{32}$ Our study confirmed this, even when the confounding effect of heart rate was reliably excluded. Whether the QT interval predicts cardiac death even in apparently healthy subjects has been examined in three population studies, but with conflicting results. In the Framingham study no association between $\mathrm{QT}_{\mathrm{c}}$ interval and mortality was found, ${ }^{8}$ whereas Schouten $e t a l^{9}$ and Dekker $e t$ $a l^{10}$ found a clear association between cardio- 
vascular mortality and prolonged $\mathrm{QT}$ in men. In healthy populations, the weakness of the QT interval as a risk factor and the use of an inadequate method of adjusting QT values for heart rate may explain the conflicting findings.

The method used to adjust the QT values for heart rate in this study resulted in excellent correction. In contrast, Bazett's QT adjustment reverses the QT-heart rate relation (fig 2), and thus the use of Bazett's $\mathrm{QT}_{\mathrm{c}}$ values in risk analysis incorporates the risk of heart rate in addition to the QT duration. In our study, the observed risk order in the modalities of deaths was the same as expected, which we judge to be confirmation of the accuracy of our method. The results are thus linked logically to the underlying theoretical electrophysiological mechanisms.

\section{CLINICAL IMPLICATIONS}

The weak association between QT interval and cardiac death in healthy subjects limits its use as a risk factor. Nevertheless, a long QT interval in subjects without signs of cardiovascular disease may reflect subclinical hypertensive or other heart disease, plus an increased risk for sudden death if heart rate is low. However, a long QT interval predicts death in men with heart disease, as does a short QT interval if they smoke. To evaluate the risk of QT duration it is essential for it to be adjusted accurately for heart rate.

This study was supported by grants from the Paavo Nurm Foundation and the Finnish Foundation for Cardiovascular Research.

1 Vaughan Williams EM. QT interval and action potential duration. Br Heart $\mathcal{F} 1982 ; 47: 513-14$

2 Vaughan Williams EM. Significance of the action potentia duration and the QT interval in the origin and treatment of ventricular arrhythmias. In: Boutros GS, Schwartz PJ, eds. Clinical aspects of ventricular repolarization. London Farrand Press, 1989:243-50.

3 Rosen MR, Wit AL, Hoffman BF. Electrophysiology and pharmacology of cardiac arrhythmias 1 . Cellular electrophysiology of the mammalian heart. Am Heart $\mathcal{f} 1974$; 88:380-5.

4 Ahnve $\mathrm{S}$, Vallin $\mathrm{H}$. Influence of heart rate and inhibition of autonomic tone on the QT interval. Circulation 1982;65: 435-9.

5 Karialainen J, Viitasalo $M$, Mänttäri $M$, Manninen V. Relation between QT intervals and heart rates from 40 to 120 beats $/ \mathrm{min}$ in rest electrocardiograms of men and a 120 beats/min in rest electrocardiograms of men and a simple method to adjust

6 Taylor GJ, Crampton RS, Gibson RS, Stebbins PT, Waldman MT, Beller GA. Prolonged QT interval at onset of of acute myocardial infarction in predicting early phase ventricular tachycardia. Am Heart $\mathcal{f} 1981 ; 102$ 16-24

7 Schwartz PJ, Moss AJ, Vincent GM, Crampton RS Diagnostic criteria for the long QT syndrome. An update. Circulation 1993;88:782-4.

8 Goldberg RJ, Bengtson J, Chen Z, Anderson KM, Locat $\mathrm{E}$, Levy D. Duration of the QT interval and total and cardiovascular mortality in healthy persons (The Framingham Heart Study experience). Am $\mathcal{f}$ Cardio 1991;67:55-8.

9 Schouten EG, Dekker JM, Meppelink P, Kok FJ,
Vandenbroucke JP, Pool J. QT interval prolongation predicts cardiovascular mortality in an apparently healthy dicts cardiovascular mortality in an apparc

10 Dekker JM, Schouten EG, Klootwijk P, Pool J, Krombout $P$. Association between QT interval and coronary heart disease in middle-aged and elderly men. The Zutphen study. Circulation 1994;90:779-85.

11 Dyer AR, Persky V, Stamler J, Paul O, Shekelle RB, Berkson DM, et al. Heart rate as a prognostic factor for coronary heart disease and mortality; findings in three Chicago epidemiological studies. Am f Epidemiol 1980; 112:736-49.

12 Reunanen A, Aromaa A, Pyörälä K, Punsar S, Maatela J, Knekt P. The Social Insurance Institution's coronary heart disease study. Baseline data and 5-year mortality experience. Acta Med Scand 1983;(suppl 673):1-120.

13 Reunanen A, Suhonen O, Aromaa A, Knekt P, Pyörälä K. Incidence of different manifestations of coronary heart disease in middle-aged Finnish men and women. Acta Med Scand 1985;218:19-26.

14 Ristola P. Resting ECG measurements and risk of cardiovascular death in Finland [in Finnish with an English summary]. Publications of the Social Insurance Institution, Finland, AL:22, Helsinki 1983.

15 Suhonen O, Reunanen A, Knekt P, Aromaa A. Risk factors for sudden and non-sudden coronary death. Acta Med Scand 1988;223:19-25.

16 Cohen J, Cohen P. Applied multiple regression/correlation analysis in behavioral sciences. New York: Wiley, 1975.

17 Cox DR. Regression models and life tables (with discussion). $\mathcal{F}$ Stat Soc B 1972;34:187-220.

8 Myerburg RJ, Kessler KM, Castellanos A. Sudden cardiac death: structure, function, and time-dependence risk. Circulation 1992;85(suppl I ):2-10.

19 Zareba W, Moss AJ, le Cessie S, Locati EH, Robinson JL Hall WJ, et al. Risk of cardiac events in family members of patients with long QT syndrome. F Am Coll Cardiol 1995;26:1685-91.

20 Cavallaro V, Petretta M, Betochi S, Salvatore C, Morgano G, Bianchi V, et al. Effects of sustained training on left ventricular structure and function in top level rowers. Eur Heart $\mathcal{F} 1$ 1993;14:898-903.

21 Kuller LH, Shemanski L, Psaty BM, Borhani N, Gardin J Haan M, et al. Subclinical disease as an independent risk Haan M, et al. Subclinical disease as an independent risk
factor for cardiovascular disease. Circulation 1995;92: factor

22 Bekheit S, Fletcher E. The effects of smoking on myocardial conduction in the human heart. Am Heart $\mathcal{f} 1976$ 91:712-20

23 Hayano J, Yamada $M$, Sakakibara Y, Fujinami $T$, Yokoyama $\mathrm{K}$, Watanabe $\mathrm{Y}$, et al. Short and long term effects of cigarette smoking on heart rate variability. $A m \mathcal{F}$ Cardiol 1990;65:84-8

24 Abildskov JA. Adrenergic effects on the QT interval of the electrocardiogram. Am Heart f 1976;92:210-16.

5 Browne KF, Zipes DP, Heger JJ, Prystowsky EN. Influence of the autonomic nervous system on the QT interval in man. Am $\mathcal{F}$ Cardiol 1982;50:1099-103.

26 Verrier RL, Thompson PL, Lown B. Ventricular vulnerability during sympathetic stimulation: role of heart rate and blood pressure. Cardiovasc Res 1974;8:602-7.

27 DeFerrari GM, Vanoli F, Stramba-Badiale M. Vagal reflexes and survival during acute myocardial ischemia in conscious dogs with a healed myocardial infarction. $A m \mathcal{F}$ Physiol 1991;261:H63-9.

28 Perkiömäki JS, Koistinen MJ, Yli-Mäyry S, Huikuri HV. Dispersion of QT interval in patients with and without susceptibility to ventricular tachyarrhythmias after previsusceptibility to ventricular tachyarrhythmias after previ-
ous myocardial infarction. $\mathcal{F}$ Am Coll Cardiol 1995;26: ous my 174 .

29 Huikuri HV, Valkama JO, Airaksinen KEJ, Seppänen T, Kessler KM, Takkunen JT, et al. Frequency domain measures of heart rate variability before the onset of nonsustained and sustained ventricular tachycardia in patients with coronary artery disease. Circulation 1993 87:1220-8.

30 Peters RW, Brooks MM, Todd L, Liebson PR, Wilhelmsen L. Smoking cessation and arrhythmic death: the CAST experience. $\mathcal{F}$ Am Coll Cardiol 1995;26:1287-92.

31 Day CP, James OF, Butler TJ, Campbell RW. QT prolongation and sudden death in patients with alcoholic liver disease. Lancet 1993;341:1423-8.

32 Algra A, Tijssen J, Roelandt J, Pool J, Lubsen J. QTc prolongation measured by standard 12-lead electrocardiography is an independent risk factor for sudden death due to cardiac arrest. Circulation 1991;83:1888-94. 